\title{
Right third toe swelling
}

\section{Ramanan Rajakulasingam ${ }^{1}$ (D) $\cdot$ Daniel Lindsay $^{2} \cdot$ Lee Bayliss $^{3} \cdot$ Asif Saifuddin $^{1}$}

Published online: 6 July 2020

(C) ISS 2020

Answer: High-grade Chondroblastic Osteosarcoma of the third toe proximal phalanx

\section{Discussion}

Figure 1 shows a mixed lytic-sclerotic lesion occupying the entire third toe proximal phalanx, with severe cortical thinning and a mineralised soft tissue mass. MRI confirms diffuse marrow infiltration with a circumferential extra-osseous component. The tumour displays low T1W and homogenous high fat suppressed PDW FSE signal intensity (SI) (Fig. 2). Pre-biopsy CT (Fig. 3) confirms the extra-osseous rim calcification. The lesion was considered indeterminate in nature. Following inconclusive needle biopsy, curettage was performed with histology displaying sections of tumour composed of spindle-toepithelioid cells with areas of chondroblastic differentiation and focal osteoid deposition. Occasional osteoclast-like giant cells were noted (Fig. 4a). The tumour cells permeated and

The case presentation can be found at https://doi.org/10.1007/s00256020-03534-5.

\author{
Ramanan Rajakulasingam \\ Ramanan.rajakulasingam1@nhs.net \\ Daniel Lindsay \\ daniel.lindsay1@nhs.net \\ Lee Bayliss \\ lee.bayliss1@nhs.net \\ Asif Saifuddin \\ Asif.saiffudin@nhs.net
}

1 Department of Radiology, Royal National Orthopaedic Hospital, Brockley Hill, Stanmore, Middlesex HA7 4LP, UK

2 Department of Histopathology, Royal National Orthopaedic Hospital, Brockley Hill, Stanmore, Middlesex HA7 4LP, UK

3 Department of Orthopaedic Surgery, Royal National Orthopaedic Hospital, Brockley Hill, Stanmore, Middlesex HA7 4LP, UK completely surrounded the necrotic host lamellar bone with osteolysis and Howship's lacunae formation (Fig. 4b). The appearances were consistent with high-grade chondroblastic osteosarcoma (OS). The patient went on to ray amputation.

OS in the feet is very rare, representing $<1 \%$ of all cases [1]. Lesions here tend to affect older males with lower grade malignancy compared with conventional OS [1]. The typical radiographic features of long-bone OS such as Codman triangle and spiculated periosteal reaction are usually not seen in the feet. Studies have suggested that the presence of periosteal reaction may be site dependant [2]. MRI features of low T1W and high fat suppressed PDW/T2/STIR SI are non-specific for OS, as is the extra-osseous component [3]. Ewing's sarcoma can present in the foot [4], but florid extra-osseous new bone formation with an intramedullary component strongly implies OS.

Two previous reports describe OS in the 5th and 3rd toe phalanges $[5,6]$ with osteoblastic and small cell differentiation, respectively. A mixed lytic-sclerotic pattern on radiography is thought to be more suggestive of small cell rather than conventional OS [7]. Osteoblastic OS is the most common subtype, presenting as an ill-defined sclerotic lesion [8], while chondroblastic OS displays more stippled and linear mineralised regions mimicking chondrosarcoma [8]. Chondroblastic OS is relatively rare, with a quoted incidence of 4.2-9\% [9]. The unusual location and atypical age group easily leads to misdiagnosis, as was the case in $50 \%$ of foot lesions reported by Biscaglia et al. who also found $>2$-year interval between symptom onset and diagnosis [10].

The main differential diagnosis for a mineralised soft tissue mass adjacent to the toes is bizarre parosteal osteochondromatous proliferation (BPOP). However, diffuse infiltration of the medullary cavity on MRI would be against this. Osteomyelitis was mentioned as a potential referral diagnosis due to overlying swelling. Chronic osteomyelitis may be an aetiological factor in OS [11], and Posthumadeboer et al. also reported their case having osteomyelitis in the same location as OS [6]. Despite the frequent lower grade of foot OS, the prognosis is no better than OS elsewhere [12]. Early diagnosis of phalangeal OS is 
important, as delay may decrease long-term survival and influence treatment, potentially resulting in poorer functional outcome and cosmetic results. Thus, in order to avoid any delay, OS should be considered when encountering any mineralising bony foot lesion regardless of patient age.

\section{Compliance with ethical standards}

Conflict of interest The authors declare that they have no conflicts of interest.

\section{References}

1. Anninga JK, Picci P, Fiocco M, et al. Osteosarcoma of the hands and feet: a distinct clinico-pathological subgroup. Virchows Arch. 2013;462(1):109-20.

2. Sun TT, Tao XF, Shi HM. Spontaneous osteosarcoma in craniomaxillofacial fibrous dysplasia: clinical and computed tomographic features in 8 cases. Oral Surg Oral Med Oral Pathol Oral Radiol. 2014;118(1):e24-31.

3. Murphey MD, Robbin MR, McRae GA, et al. The many faces of osteosarcoma. Radiographics. 1997;17(5):1205-31.

4. Togral G, Arıkan M, Benzer E, et al. Ewing sarcoma of the proximal phalanx of the foot: a rare case report. Hippokratia. 2015;19(1):82-4.
5. Matsunobu T, Bekki H, Harimaya K, et al. Osteosarcoma of the middle and distal phalanges of the little toe with a cancerous ulcer. Int J CAse Rep Images. 2016;7(3):185-9.

6. Posthumadeboer J, Graat HC, Bras J, et al. Small cell osteosarcoma of a toe phalanx: a case report and review of literature. J Orthop Surg Res. 2010;5:36.

7. Edeiken J, Raymond AK, Ayala AG. Small-cell osteosarcoma. Skelet Radiol. 1987;16:621-8.

8. Yen CH, Chang CY, Teng MM, et al. Different and identical features of chondroblastic osteosarcoma and chondrosarcoma: highlights on radiography and magnetic resonance imaging. J Chin Med Assoc. 2009;72(2):76-82.

9. Dorfman HD, Czerniak B. Bone tumors. St Louis: Mosby; 1997. p. 128-219.

10. Biscaglia R, Gasbarrini A, Bohling T, et al. Osteosarcoma of the bones of the foot: an easily misdiagnosed malignant tumor. Mayo Clin Proc. 1998;73:842-7.

11. Horvai A, Unni KK. Premalignant conditions of bone. J Orthop Sci. 2006;11:412-23.

12. Sneppen O, Dissing I, Heerfordt J, et al. Osteosarcoma of the metatarsal bones: review of the literature and report of a case. Acta Orthop Scand. 1978;49:220-3.

Publisher's note Springer Nature remains neutral with regard to jurisdictional claims in published maps and institutional affiliations. 